\title{
Yarı Kurak İklim Koşullarında Bazı Pamuk Çeşitlerinde Verim ve Farklı Hasat Tarihlerine Göre Tohum ve Lif Özelliklerinin Belirlenmesi
}

\author{
Osman ÇOPUR ${ }^{1 *}$, i. Halil BiRGÜ $L^{2}$ \\ ${ }^{1}$ Harran Üniversitesi Ziraat Fakültesi Tarla Bitkileri Bölümü, Şanlıurfa \\ ${ }^{2}$ Harran Üniversitesi Fen Bilimleri Enstitüsü Tarla Bitkileri ABD, Şanlıurfa \\ "Sorumlu yazar: ocopur@harran.edu.tr
}

Öz

Pamukta verim ve bitki gelişimi, genetik ve çevre koşullarının interaksiyonu ile oluşmaktadır. Bitki üzerinde farkı meyve dallarında oluşan liflerin gelişimi ve teknolojik özellikleri farklılık göstermektedir. Bu çalışmada, bazı pamuk çeşitlerinde verim ve farklı tarihlerde hasat edilen kütlü pamukların lif özelliklerini belirlemek amacıyla, Harran Üniversitesi Ziraat Fakültesi Eyyübiye Kampüsü deneme alanında 2006 ve 2007 yılı yetiştirme sezonunda yürütülmüştür. Gossypium hirsutum L. türüne ait 10 pamuk çeşidi bitki materyali olarak kullanılmıştır. Deneme, tesadüf blokları deneme deseninde 3 tekerrürlü olarak kurulmuş, her parsel 6 sıralı, sıra arası $70 \mathrm{~cm}$ ve bitkiler $15-20 \mathrm{~cm}$ sıra üzeri mesafesinde seyreltilmiştir. Çalışma soncunda; kütlü pamuk verimi yönünden Stoneville-453 ve BA-119, erkencilik oranı yönünden Fantom ve DPL-388, bitki boyu yönünden Sayar-314 ve Erşan-92, 100 tohum ağırlığı yönünden GW Teks, çırçır randımanı yönünden BA-119 ve DPL-388, mot sayısı yönünden BA-119 ve Stoneville-453, nep sayısı yönünden SG-125 ve Stoneville-453, lif uzunluğu yönünden GW Teks ve Carmen, lif inceliği yönünden Fantom çeşidi, lif kopma dayanıklılığı yönünden GW Teks ve ortalama lif üniformite oranı yönünden GW Teks ve Erşan-92 ve lif elastikiyeti oranı yönünden ise Fantom ve DPL388 çeşitlerinin diğer çeşitlere göre üstün olduğu ve ıslah çalışmalarında ebeveyn olarak kullanılabileceği saptanmıştır. Ayrıca, farklı pamuk çeşitlerinin ve farklı tarihlerde toplanan kütlülerin ayrı depolarda depolanmasının uygun olacağı belirlenmiştir.

Anahtar Kelimeler: Pamuk, Yarı-kurak, Verim, Hasat tarihleri, Lif özellikleri

\section{Determination of Yield and Fiber Characteristics for Different Harvesting Dates in Some Cotton Varieties under the Semi Arid Climatic Condition}

\begin{abstract}
Yield and plant development of cotton occur over the interaction of genetic and environmental conditions. Growth and technological characteristics of fibers which grow on different fruit branches of the plant differ from one to another. This study was carried out at the research area of Harran University, Faculty of Agriculture, Eyyübiye Campus in 2006 and 2007 growing season to determine the yield and fiber characteristics of the some cotton cultivars with harvested at different times. Ten cotton varieties (Gossypium hirsutum L.) were used as the plant material. The trial was carried out in randomized complete blocks design with 3 replications; with consist of 6 rows in each plot, $70 \mathrm{~cm}$ row spacing and $15-20 \mathrm{~cm}$ intrarow spacing. As a result of the study, the cultivars found to be superior among others are Stoneville-453 and BA-119 for the yield of seed cotton; Fantom and DPL-388 for earliness ratio, Sayar-314 and Erşan-92 for plant height, GW Teks for seed index, BA-119 and DPL-388 for ginning outturn, BA-119 and Stoneville-453 for number of motes, SG-125 and Stoneville-453 for number of naps, GW Teks and Carmen for the fiber length, Fantom for the fineness of fibers, GW Teks for the fiber strength, GW Teks and Erşan-92 for the fiber uniformity, and Fantom and DPL-388 for fiber elongation, and that they can be preferred as parents in cotton improvement. Furthermore, different cotton cultivars and seed cotton harvested in different dates should be stored in separate storage houses.
\end{abstract}

Key Words: Cotton, Semi-arid, Yield, Harvesting date, Fiber characteristics 
Giriş

Ülkemizde 1984-85 yılları arasında pamuk ekim alanı 706000 ha iken, Güneydoğu Anadolu Bölgesinde artan sulama olanakları sonucunda dahi ekim alanlarının artmasının tersine, azalarak 2015 yılında 435000 ha'a düşmüştür (Çopur, 2016). Son yıllarda dünya pamuk fiyatlarının düşmesi ve üretim maliyetlerinin giderek yükselmesi nedeniyle ekim alanlarının tekrar artması yoluyla üretim artışı beklenmemelidir. Ülkemizde, üretim artışını sağlamanın en geçerli yolu girdilerin arttırımaksızın verimin arttırılması ile üretim maliyetinin düşürülmesidir (Özbek ve ark., 2005). Üretim maliyetlerinin azaltılmasında girdilerin optimum kullanımı yanında, çeşit seçimi, uygun ebeveynlerin belirlenmesi ve lif pamuk üretim aşamalarında lif kalite özelliklerinin muhafazası önem arz etmektedir.

Pamuk bitkisi, çiçeklenme başlangııından, büyümenin sona ermesine kadar çiçek oluşturabilmektedir. Bitki üzerinde ilk çiçek ile son çiçek arasında yaklaşık 2-2.5 aylık bir süre olabilmektedir. Kozaların olgunlaşma süreleri, çeşit ve çevre koşullarına bağlı olarak değişebilmektedir. Çiçeklenme ve koza olgunlaşma süresinin uzun bir zaman dilimi içinde olması, değişik konumda oluşan kozaların, farklı koşullarda gelişmesine neden olabilmektedir. Gelişme koşullarındaki iç ve dış farklılıklar, kozaların teknolojik özelliklerinde farklılıklar oluşturabilmektedir. Dolayısıla farklı tarihlerde toplanan pamukların birlikte depolanması ve işlenmesi sonucu nihai ürün olan tekstil ürünlerinde kalite sorunu ortaya çıkmaktadır (Çopur ve ark., 1999).

Kütlü pamuğun çırçırlanması ile tohum ve lif unsurları birbirinden ayrılmaktadır. Bu iki unsur; taraklanma, çiçeklenme dönemleri ile hasat depolama ve çırçırlama aşamalarında, kalite yönünden birbirlerine etkili olmaktadırlar. Özellikle, tohum kalitesi lif kalitesine olumlu ya da olumsuz yönde etkileyebilmektedir. Pamuk lifleri, tohum kabuğu dış epidermis hücrelerinin dışa doğru uzaması ile oluşur. Bu nedenle, tohum taslağının (ovule) döllenmesi, embriyosunun gelişmesi ve olgunlaşması ile liflerin uzama ve bir başka deyişle lif teknolojik özelliklerinin oluşumu ve gelişimi arasında sıkı bir ilişki bulunmaktadır.

Döllenmemiş tohum taslakları veya gelişmesi çeşitli nedenlerle engellenmiş olan embriyolara "mot" denilmektedir. Mot üzerindeki lifler, değişik uzunlukta olabilmesine karşın olgunlaşmamış olarak tanımlanmaktadır. Kısa liflere sahip olan "mot" lar, gerek çırçır ve gerekse iplik işletmelerinin temizleyici sistemlerinde elemine edilebilmekte; buna karşılık, "mot" üzerindeki uzun ancak olgunlaşmamış lifler ise düğümcük (nep) oluşumuna ve dolayısı ile iplik, dokuma ve hazır giyimde boyanmayan noktacıklar "White Speck" ortaya çıkmasına neden olmaktadırlar. Şanlıurfa koşullarında pamuğun tozlanma ve döllenme dönemindeki yüksek sıcaklara karşı tepkileri farklı olmakta, mot ve nep oluşumu kaçınılmaz olmaktadır. Bu yüzden üretimi yapılan çeşitlerde mot ve nep miktarının çeşit ve hasat dönemlerine göre saptanmasında yarar bulunmaktadır.

Bu çalışma, Güneydoğu Anadolu Bölgesi standart pamuk çeşitlerinden Sayar-314, Erşan-92, BA-119, Sure Grow-125, Stoneville453, Carmen, DPL-388, GW Teks, DPL-5111 ve Fantom pamuk (Gossypium hirsutum L.) çeşitlerinin Harran Ovası koşullarında verim, erkencilik ve farklı hasat devrelerine göre; mot miktarı, tohum ve lif teknolojik özelliklerinin saptanması amacıyla ele alınmıştır. 


\section{Materyal ve Metot}

Deneme, Harran Üniversitesi Ziraat Fakültesi Eyyübiye Kampüsü deneme alanında 2006 ve 2007 yıllarında yürütülmüştür. Anılan alanın denizden ortalama yüksekliği $465 \mathrm{~m}$ olup, $37^{\circ} 08^{\prime} \mathrm{N}$ enlem ve $38^{\circ} 46^{\prime} \mathrm{E}$ boylamlarında yer almaktadır. Deneme alanı killi (\%60), organik madde oranı düşük (\%1.2), $\mathrm{pH}$ değeri 7.2' dir (Çizelge 1). Deneme alanı ikizce toprak serisi
(Vertic Calciorthid Aridisol) olarak sınıflandırılmıştır (Anonim, 2006). Harran ovası, yarı kurak iklim koşullarına sahip olup, yazları sıcak ve kurak, kışları ise ılık ve yağışlıdır. Yazın sıcaklık $44.8{ }^{\circ} C^{\prime}$ ye kadar çıkabilmektedir. Bölgede toplam yăı̆ş miktarı 2006 ve 2007 yıllarında 355.2 ve $364.2 \mathrm{~mm}$ olarak gerçekleşmiştir (Çizelge 2). Uzun yıllar ortalama sıcaklık $18.3{ }^{\circ} \mathrm{C}$, ortalama nem $\% 50.3$ ve ortalama rüzgar hızı $2.2 \mathrm{~m} \mathrm{~s}^{-1^{\prime}}$ dir (Anonim, 2009).

Çizelge 1. Deneme alanına ait bazı toprak özellikleri

Table 1. Several soil properties of the study area

\begin{tabular}{|c|c|c|c|c|c|c|c|c|c|c|c|}
\hline \multirow[t]{2}{*}{$\begin{array}{l}\text { Derinlik } \\
(\mathrm{cm})\end{array}$} & \multirow[t]{2}{*}{$\begin{array}{c}\mathrm{HA} \\
\left(\mathrm{g} \mathrm{cm}^{-3}\right)\end{array}$} & \multirow[t]{2}{*}{$\begin{array}{l}\text { OM } \\
(\%)\end{array}$} & \multicolumn{3}{|c|}{$\begin{array}{c}\text { Toprak Partiküllerinin } \\
\text { Dağılımı (\%) }\end{array}$} & \multirow[t]{2}{*}{$\mathrm{pH}$} & \multirow[t]{2}{*}{$\begin{array}{c}\mathrm{N} \\
\left(\mathrm{kg} \mathrm{ha}^{-1}\right)\end{array}$} & \multirow[t]{2}{*}{$\begin{array}{c}\mathrm{P}_{2} \mathrm{O}_{5} \\
\left(\mathrm{~kg} \mathrm{ha}^{-1}\right)\end{array}$} & \multirow[t]{2}{*}{$\begin{array}{c}\mathrm{K}_{2} \mathrm{O} \\
\left(\mathrm{kg} \mathrm{ha}^{-1}\right)\end{array}$} & \multirow[t]{2}{*}{$\begin{array}{c}\text { TK } \\
(\%)\end{array}$} & \multirow[t]{2}{*}{$\begin{array}{l}\text { SSN (\%) } \\
\text { PWP(\%) }\end{array}$} \\
\hline & & & Kum & Silt & Kireç & & & & & & \\
\hline $0-30$ & 1.37 & 1.2 & 7 & 34 & 59 & 7.3 & 25 & 27 & 1280 & 31.5 & 22.2 \\
\hline $30-60$ & 1.40 & 0.8 & 17 & 25 & 58 & 7.2 & 12 & 20 & 900 & 31.8 & 22.6 \\
\hline $60-90$ & 1.43 & 0.6 & 20 & 21 & 59 & 7.2 & 6 & 17 & 810 & 32.3 & 21.5 \\
\hline $90-120$ & 1.43 & 0.5 & 19 & 20 & 62 & 7.2 & - & - & - & 32.5 & 21.5 \\
\hline
\end{tabular}

Denemeler tesadüf blokları deneme desenine göre 3 tekerrürlü olarak kurulmuştur. Deneme materyali olarak seçilen pamuk çeşitleri (Sayar-314, Erşan-92, BA-119, SG-125, Stoneville-453, Carmen, DPL-388, GW Teks, DPL-5111 ve Fantom) Güneydoğu Anadolu Bölgesi pamuk alanları için tescil edilen çeşitlerdir.

Ekim işlemi, 2006 yılında 05 Mayıs ve 2007 yllında ise 7 Mayıs tarihinde pamuk deneme mibzeri ile $70 \mathrm{~cm}$ sıra arası mesafesinde, $10 \mathrm{~m}$ uzunluğunda ve 6 'şar sıralı olarak yapılmıştır. Çıkıştan sonra bitkiler 4-5 yapraklı olduğu dönemde sıra üzeri mesafe $15-20 \mathrm{~cm}$ olacak şekilde (her sırada 50-60 bitki) seyreltilmiştir. Deneme yıllarında yetiştirme sezonu boyunca, bitkiler 2 kez el, 3 defa traktör çapası ile çapalanmış ve 10 defa karık usulü ile sulanmıştır. Ekimle birlikte dekara saf olarak $8 \mathrm{~kg}$ azot ve $8 \mathrm{~kg}$ fosfor (20:20:0 kompoze gübre) ile çiçeklenme başlangıcında ise $8 \mathrm{~kg}$ azot (\%33 Amonyum nitrat) üst gübre olarak uygulanmıştır. Denemede uygulanan kültürel işlemler; bölgede yapılan çalışmalar esas alınarak yapılmıştır. Hasatlar; 2006 ve 2007 yıllarında, birinci el hasat 5 Eylül, ikinci el hasat ise 20 Eylül ve üçüncü el hasat ise 5 Ekim tarihinde olmak üzere üç defada ve elle yapılmıştır.

Çalışmada incelenen kütlü pamuk verimi, erkencilik oranı, bitki boyu, çırçır randımanı ve 100 tohum ağırlığı Worley ve ark., (1976), mot sayısı Anthony ve Coulhoun (1996), nep sayısı, lif uzunluğu, lif inceliği, lif kopma dayanıklılığı, lif üniformite oranı, lif elastikiyeti oranı ve renk durumu (sayısal değer olarak) özellikleri HVI Specktrum ve AFIS-N modülünde (Anonim, 1997) yöntemleri uyarınca saptanmıştır. 
Çizelge 2. 2006 ve 2007 yılları pamuk yetiştirme sezonunda bazı iklim özellikleri

Table 2. Climatic data of the cotton crop growing season for the years of 2006 and 2007

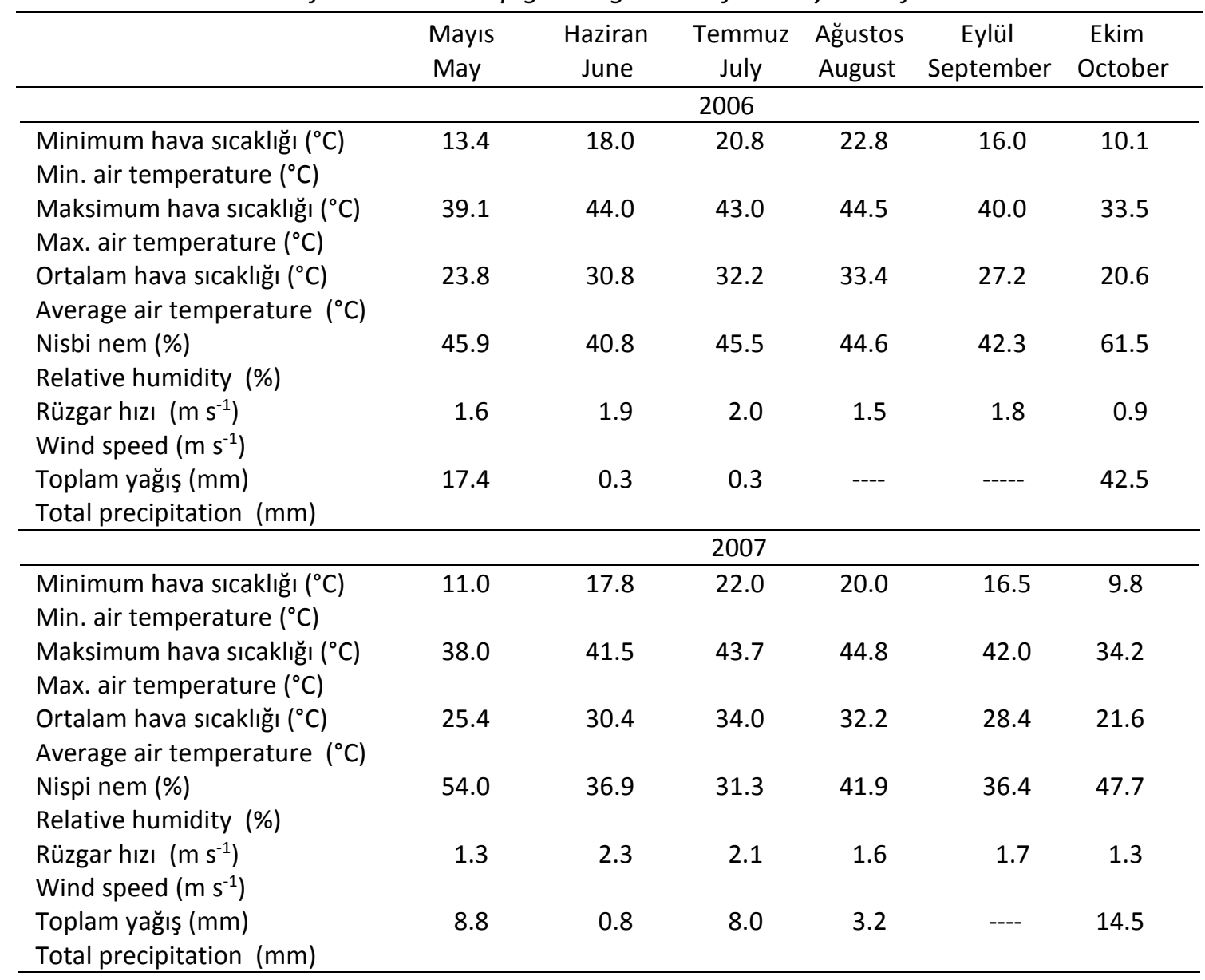

Elde edilen verilerden kütlü pamuk verimi, erkencilik oranı ve bitki boyu değerleri MSTAT-C paket programı kullanılarak tesadüf blokları deneme deseninde, diğer özellikler ise bölünmüş parseller deneme deseninde (çeşitler ana parsel ve hasat tarihleri ise alt parsel olmak üzere), her yıl ayrı ayrı analiz edilmiş ve ortalamalar LSD testine göre karşılaştırılmıştır (Anonim, 1989).

\section{Araştırma Bulguları ve Tartışma}

Çalışmada kütlü pamuk verimi $\left(\mathrm{kg} \mathrm{da} \mathrm{d}^{-1}\right)$, erkencilik oranı (\%) ve bitki boyu $(\mathrm{cm})$ değerlerine ilişkin ortalama değerler ve LSD (0.05) testine göre oluşan gruplar Çizelge 3'de, çırçır randımanı (\%), 100 tohum ağırlığı (g) ve mot sayısına (mote koza-1) ilişkin ortalama değerler ve LSD (0.05) testine göre oluşan gruplar Çizelge 4 'te, nep sayısı (adet $\left.\mathrm{g}^{-1}\right)$, lif uzunluğu $(\mathrm{mm})$ ve lif inceliğine (micronaire) ilişkin ortalama değerler ve LSD (0.05) testine göre oluşan gruplar Çizelge 5 'te ve lif kopma dayanıklılı̆ı $\left(\mathrm{g} \mathrm{tex}^{-1}\right.$ ), lif üniformite oranı (\%) ve lif elastikiyeti oranı (\%) ile LSD (0.05) testine göre oluşan gruplar Çizelge $6^{\prime} \mathrm{da}$, çeşit ve hasat tarihlerine göre elde edilen sayısal renk değerleri Çizelge 7 'de verilmiştir.

Çizelge 3 'den, ortalama kütlü pamuk veriminin 2006 yılında $328.19 \mathrm{~kg} \mathrm{da}^{-1}$ ile $487.41 \mathrm{~kg} \mathrm{da}^{-1}$ arasında değiştiği, ortalama $402.18 \mathrm{~kg} \mathrm{da}^{-1}$ olduğu, 2007 yllında ise $318.31 \mathrm{~kg} \mathrm{da}^{-1}$ ile $454.12 \mathrm{~kg} \mathrm{da}^{-1}$ arasında değiştiği ve ortalamanın $388.24 \mathrm{~kg} \mathrm{da}^{-1}$ 
olduğu izlenebilmektedir. Aynı çizelgeden, her iki yılda da, en yüksek kütlü pamuk veriminin Stoneville-453 çeşidinden, en düşük kütlü pamuk verimin ise SG-125 çeşidinden elde edildiği görülmektedir. LSD testine göre; her iki yılda da çeşitler arasında önemli düzeyde (0.01) bir farklılık bulunduğu ve farklı verim gruplarının olduğu saptanmıştır (Çizelge 3). Bu durum, çeşitlerin iklim ve toprak koşullarına olan uyum farklııklarının yanında genotipik özellikten de kaynaklanmış olabilir. Benzer bulgular, Çopur (1995), Karademir ve ark. (2003), Çopur (2006) ve Liu ve ark. (2013) tarafından saptanmıştır. Ayrıca, Demirel ve ark. (2016) tarafından yapılan sıcaklığa toleranslık çalışmasında, Stoneville- 453 ve BA-119 çeşitlerinin tarla koşullarına paralel olarak sıcaklığa toleranslı olduğu, bu nedenle anılan çeşitlerin verim durumları yanında sıcaklığa toleranslı çeşit ıslahında ebeveyn olarak seçilebileceği kanaati oluşmuştur.

Çizelge 3. 2006 ve 2007 Yıllarında, bazı pamuk çeşitlerinde elde edilen ortalama kütlü pamuk verimi, erkencilik oranı ve bitki boyu değerleri ile LSD testine göre oluşan gruplar

Table 3. Means of seed cotton yields, earliness ratio and plant height according to some cultivars and LSD testing groups in years to 2006 and 2007

\begin{tabular}{|c|c|c|c|c|c|c|}
\hline \multirow[t]{2}{*}{$\begin{array}{l}\text { Çeşitler } \\
\text { Varieties }\end{array}$} & \multicolumn{2}{|c|}{$\begin{array}{c}\text { Kütlü Pamuk Verimi }\left(\mathrm{kg} \mathrm{da}^{-1}\right) \\
\left.\text { Seed Cotton Yield } \mathrm{kg} \mathrm{da}^{-1}\right)\end{array}$} & \multicolumn{2}{|c|}{$\begin{array}{c}\text { Erkencilik Oranı (\%) } \\
\text { Earliness Ratio (\%) }\end{array}$} & \multicolumn{2}{|c|}{$\begin{array}{c}\left.\text { Bitki Boyu (cm bitki }{ }^{-1}\right) \\
\text { Plant Height }\left(\mathrm{cm} \text { plant }^{-1}\right)\end{array}$} \\
\hline & 2006 & 2007 & 2006 & 2007 & 2006 & 2007 \\
\hline Stoneville-453 & $487.41 a^{*}$ & $454.12 \mathrm{a}$ & $96.00 \mathrm{bcd}$ & $95.30 \mathrm{ab}$ & $85.30 d$ & $78.37 \mathrm{c}$ \\
\hline SG-125 & $328.19 \mathrm{f}$ & $318.31 \mathrm{e}$ & $96.76 \mathrm{abc}$ & $92.87 \mathrm{~b}$ & $85.83 d$ & $80.13 c$ \\
\hline BA-119 & $455.33 a b$ & $432.14 a b$ & $97.73 a b$ & $95.57 a b$ & $86.10 d$ & $79.63 \mathrm{c}$ \\
\hline Carmen & 386.22 de & $391.73 \mathrm{c}$ & $87.31 \mathrm{f}$ & $81.35 c$ & $94.20 \mathrm{c}$ & $82.90 \mathrm{c}$ \\
\hline DPL-388 & 394.16 cde & $386.74 \mathrm{c}$ & $98.01 \mathrm{a}$ & $98.72 a b$ & $86.93 \mathrm{~cd}$ & $78.83 \mathrm{c}$ \\
\hline DPL-5111 & $359.97 \mathrm{e}$ & $345.14 d$ & $97.58 a b c$ & $96.28 a b$ & $88.27 \mathrm{~cd}$ & $81.03 \mathrm{c}$ \\
\hline GW Teks & $338.54 \mathrm{f}$ & 323.15 de & $94.39 \mathrm{de}$ & $94.20 a b$ & $92.00 \mathrm{~cd}$ & $84.90 \mathrm{c}$ \\
\hline Fantom & $408.98 \mathrm{bcd}$ & 387.62 c & $98.33 \mathrm{a}$ & 98.97 a & $106.57 \mathrm{~b}$ & 114.73 a \\
\hline Sayar-314 & $423.32 \mathrm{bcd}$ & $420.91 \mathrm{~b}$ & $93.81 \mathrm{e}$ & $92.95 \mathrm{~b}$ & 117.87 a & $109.13 \mathrm{ab}$ \\
\hline Erşan-92 & 439.69 bc & $423.53 \mathrm{~b}$ & $95.96 \mathrm{~cd}$ & $94.84 a b$ & $116.67 \mathrm{a}$ & $103.63 b$ \\
\hline $\begin{array}{l}\text { Ortalamalar } \\
\text { Means }\end{array}$ & 402.18 & 388.34 & 95.59 & 94.11 & 95.97 & 89.33 \\
\hline $\mathrm{LSD}(0.05)$ & 46.72 & 24.03 & 1.75 & 5.94 & 7.62 & 9.59 \\
\hline CV (\%) & 6.77 & 3.61 & 6.77 & 3.68 & 4.63 & 6.26 \\
\hline
\end{tabular}

*: Aynı harf grubu içerisinde yer alan konular arasında (dikey) istatistiki olarak önemli düzeyde (0.05) bir farklılık bulunamamıştır. *Means shown with the same column are not significantly differently at $p=0.05$ probability level.

Çizelge 3'den, çeşitlere göre ortalama birinci el kütlü pamuk oranının 2006 yılında \% 87.31 ile \% 98.33 arasında değiştiği; ortalamanın \% 95.59 olduğu, 2007 yılında ise \% 81.35 ile \% 98.97 arasında değiştiği ve ortalamanın \% $\quad 94.11 \quad$ olduğu izlenebilmektedir. Aynı çizelgeden, her iki yılda da, Fantom çeşidinin en yüksek, Carmen çeşidinin ise en düşük birinci el kütlü pamuk oranını oluşturduğu izlenebilmektedir. Yapılan LSD testi sonucunda; birinci el kütlü pamuk oranı yönünden çeşitler arasında önemli bir farklılı̆ın olduğu saptanmıştır. LSD (en küçük önemli fark) testine göre, farklı erkencilik gruplarının oluştuğu belirlenmiştir. Fantom ve DPL-388 çeşitleri birinci el kütlü pamuk oranı sıralamasında ilk sırada yer almaktadırlar. Bu farklıık çeşitlerin toprak ve iklim koşullarına göre farklı tepki göstermeleri yanında, çeşitlerin genetiksel farklılıklarından da kaynaklanmış olabilir. 
Ayrıca, erkencilik yönünden yapılacak ıslah çalışmalarında Fantom ve DPL-388 çeşitleri ebeveyn olarak seçilebilir.

Çizelge 3'ten, bitki boyunun 2006 yılında $85.30 \mathrm{~cm}$ ile $117.87 \mathrm{~cm}$ arasında ve 2007 yılında ise $78.37 \mathrm{~cm}$ ile $114.73 \mathrm{~cm}$ arasında değiştiği ve bitki boyu yönünden çeşitler yönünden önemli düzeyde bir farklılık olduğu saptanmıştır. 2006 yılında en uzun boylu çeşidin Sayar-314 $(117.87 \mathrm{~cm})$ ve 2007 yılında ise Fantom $(114.73 \mathrm{~cm})$ çeşidi olduğu bu çeşidi Erşan-92 çeşidinin izlediği Çizelge 3'te görülebilmektedir. Her iki yılda da Sayar314, Erşan-92 ve Fantom çeşitlerinin diğer çeşitlere göre daha fazla boylandığı, denemede kullanılan çeşitlerin farklı olgunlaşma grupları ve farklı genotipik yapıya sahip olmalarından dolayı çeşitler arasında farklı bitki boyu grupları oluşmuştur. Benzer bulgular Çopur (1999), Çopur (2006) ve Baran (2013) tarafından da belirtilmektedir.

Çizelge 4'den, çırçır randımanının 2006 yılında \% 38.25 ile \% 41.24 arasında değiştiği, ortalama \% 39.79 olduğu, 2007 yılında ise \% 38.55 ile \% 42.23 arasında değiştiği ve ortalamanın $\quad \% \quad 40.44 \quad$ olduğu izlenebilmektedir. Aynı çizelgeden, en yüksek çırçır randımanı değerinin 2006 yılında DPL388, GW Teks ve BA-119 çeşitleri, 2007 yılında ise BA-119 ve DPL-388 çeşitleri, en düşük çırçır randımanının ise, DPL 5111 ve Fantom çeşitlerinden elde edildiği izlenebilmektedir. LSD testine (en küçük önemli fark) göre, farklı çırçır randımanı gruplarının oluştuğu belirlenmiştir. DPL-388 çeşidi çırçır randımanı sıralamasında ilk sırada yer almaktadır. Çeşitler arasındaki farklıık, çeşitlerin farklı genotipik yapılara sahip olmasından kaynaklanmış olabilir. Benzer bulgular, Çopur (1995), Karademir ve ark. (2003) ve Çopur (2006) tarafından da saptanmıştır. Çırçır randımanı yönünden yapılacak ıslah çalışmalarında, DPL-388, GW Teks, BA-119, Sayar-314, Erşan-92 ve SG-125 çeşitleri ebeveyn olarak seçilebileceği kanaati oluşmuştur. Ayrıca, hasat tarihlerinin çırçır randımanı üzerine önemli bir etkisinin 2006 yılında olmadığı ve 2007 yılında ise önemli olduğu ve hasadın gecikmesiyle çırçır randımanının azda olsa azaldığı saptanmıştır. Bu durum, pamuk bitkisi üzerinde farklı meyve dalları üzerinde oluşan kozalardaki kütlü pamukların lif miktarının azalmasından kaynaklanmış olabilir.

Çizelge 4'ten, çeşitlere göre ortalama 100 tohum ağırlığının 2006 yılında 7.55 g ile $10.27 \mathrm{~g}$ arasında değiştiği, ortalama $8.69 \mathrm{~g}$ olduğu, 2007 yılında ise $8.42 \mathrm{~g}$ ile $11.85 \mathrm{~g}$ arasında değiştiği ve ortalamanın $9.74 \mathrm{~g}$ olduğu izlenebilmektedir. Aynı çizelgeden, en yüksek 100 tohum ağırlığının her iki yılda da GW Teks çeşidinden elde edildiği; en düşük 100 tohum ağırlığının ise, BA-119 çeşidinden elde edildiği izlenebilmektedir. LSD (en küçük önemli fark) testine göre, farklı tohum ağırlığı gruplarının oluştuğu belirlenmiştir. Çizelge 4'den, 100 tohum ağırlığının çeşitlere göre değiştiği, hasat tarihinin gecikmesiyle 100 tohum ağırlığının azaldığı izlenebilmektedir. Bu durum, pamuk bitkisinde tohum ağırlığının içten dışa ve alttan yukarı doğru azalmasından kaynaklanabilir. Ayrıca, geç açan çiçeklerde yeterli miktarda fotosentez olmaması sonucunda tohumlar yeterince gelişmemekte dolayısıyla, tohum ağırlığının azalmasına neden olmaktadır. Benzer bulgular Meredith ve Bridge (1973) ve Civaroğlu (1993) ve Çopur ve ark. (1999) tarafından da bildirilmektedir. 
Çizelge 4. 2006 ve 2007 yıllarında, farklı pamuk çeşitlerinde ve farklı hasat tarihlerinde elde edilen ortalama çırçır randımanı, 100 tohum ağırlığı ve mot sayıs değerleri ile LSD testine göre oluşan gruplar

Table 4. Means of ginning outturn, seed index and mote number according to some cultivars and harvesting dates and LSD testing groups in years to 2006 and 2007

\begin{tabular}{|c|c|c|c|c|c|c|}
\hline \multirow{2}{*}{$\begin{array}{l}\text { Çeşitler } \\
\text { Varieties }\end{array}$} & \multicolumn{2}{|c|}{$\begin{array}{l}\text { Çırçır Randımanı (\%) } \\
\text { Ginning Outturn (\%) }\end{array}$} & \multicolumn{2}{|c|}{$\begin{array}{l}100 \text { Tohum Ağırlığı (g) } \\
\text { Seen Index }(g)\end{array}$} & \multicolumn{2}{|c|}{$\begin{array}{c}\text { Mote Sayısı (adet koza }{ }^{-1} \text { ) } \\
\text { Mote Number (number boll }{ }^{-1} \text { ) }\end{array}$} \\
\hline & 2006 & 2007 & 2006 & 2007 & 2006 & 2007 \\
\hline Stoneville-453 & $38.65 b^{*}$ & $38.90 \mathrm{e}$ & $8.99 \mathrm{c}$ & $9.72 \mathrm{c}$ & $4.09 \mathrm{bcd}$ & $3.38 \mathrm{~d}$ \\
\hline SG-125 & $39.74 a b$ & $41.06 \mathrm{bc}$ & $7.69 \mathrm{fg}$ & $9.30 \mathrm{~d}$ & $4.44 a b c$ & $4.47 c$ \\
\hline BA-119 & $40.79 \mathrm{a}$ & $42.23 \mathrm{a}$ & $7.55 \mathrm{~g}$ & $8.42 \mathrm{f}$ & $3.31 \mathrm{f}$ & $3.66 \mathrm{~d}$ \\
\hline Carmen & $39.86 \mathrm{ab}$ & $41.02 \mathrm{c}$ & $8.77 \mathrm{c}$ & $9.53 \mathrm{~cd}$ & 3.91 cde & $4.64 \mathrm{c}$ \\
\hline DPL-388 & $41.24 \mathrm{a}$ & $41.86 \mathrm{ab}$ & $8.28 \mathrm{de}$ & $8.85 \mathrm{e}$ & 3.83 def & $4.39 c$ \\
\hline DPL-5111 & $38.25 b$ & $39.16 \mathrm{de}$ & $8.72 \mathrm{~cd}$ & $9.28 \mathrm{~d}$ & 3.49 ef & $3.70 \mathrm{~d}$ \\
\hline GW Teks & $41.09 \mathrm{a}$ & $40.91 \mathrm{c}$ & $10.27 \mathrm{a}$ & $11.85 \mathrm{a}$ & $4.88 \mathrm{a}$ & $6.06 a$ \\
\hline Fantom & $38.29 b$ & $38.55 \mathrm{e}$ & 8.00 ef & $9.35 \mathrm{~cd}$ & $4.38 \mathrm{abcd}$ & $3.47 d$ \\
\hline Sayar-314 & $40.06 a b$ & $40.87 c$ & $9.58 \mathrm{~b}$ & $10.42 b$ & $4.67 a b$ & $4.61 \mathrm{c}$ \\
\hline Erşan-92 & $39.91 a b$ & $39.82 \mathrm{~d}$ & $9.00 \mathrm{c}$ & $10.69 \mathrm{~b}$ & $4.78 \mathrm{a}$ & $5.24 \mathrm{~b}$ \\
\hline $\begin{array}{l}\text { Ortalamalar } \\
\text { Means }\end{array}$ & 39.79 & 40.44 & 8.69 & 9.74 & 4.18 & 4.36 \\
\hline $\operatorname{LSD}(0.05)$ & 1.869 & 0.827 & 0.448 & 0.382 & 0.598 & 0.354 \\
\hline \multicolumn{7}{|l|}{$\begin{array}{l}\text { Hasat Tarihleri } \\
\text { Harvesting dates }\end{array}$} \\
\hline $\begin{array}{l}5 \text { Eylül } \\
5 \text { September }\end{array}$ & 39.51 & $40.89 a$ & $10.41 a b$ & $10.08 \mathrm{a}$ & $3.91 \mathrm{~b}$ & $3.95 \mathrm{~b}$ \\
\hline $\begin{array}{l}20 \text { Eylül } \\
20 \text { September }\end{array}$ & 40.50 & $40.59 \mathrm{a}$ & $8.63 \mathrm{~b}$ & $9.74 b$ & $3.96 \mathrm{~b}$ & $4.13 b$ \\
\hline $\begin{array}{l}5 \text { Ekim } \\
5 \text { October }\end{array}$ & 39.36 & $39.84 \mathrm{~b}$ & $7.89 \mathrm{c}$ & $9.40 \mathrm{c}$ & $4.66 \mathrm{a}$ & $5.01 \mathrm{a}$ \\
\hline $\begin{array}{l}\text { Genel Ortalama } \\
\text { Grand Mean }\end{array}$ & 39.79 & 40.44 & 8.69 & 9.74 & 4.18 & 4.36 \\
\hline $\operatorname{LSD}(0.05)$ & Ö.D. & 0.440 & 0.247 & 0.192 & 0.318 & 0.193 \\
\hline CV (\%) & 5.26 & 2.08 & 5.45 & 3.79 & 14.6 & 8.49 \\
\hline
\end{tabular}

*: Aynı harf grubu içerisinde yer alan konular arasında istatistiki olarak önemli düzeyde (0.05) bir farklılık bulunamamıştır.

*Means shown with the same column are not significantly differently at $p=0.05$ probability level.

Çizelge 4.'den, ortalama mot sayısının 2006 yılında 3.31-4.78 adet koza ${ }^{-1}$ arasında değiştiği, ortalama 4.18 adet koza ${ }^{-1}$ olduğu, 2007 yılında ise 3.38 - 6.06 adet koza ${ }^{-1}$ arasında değiştiği ve ortalamanın 4.36 adet koza $^{-1}$ olduğu; en yüksek mot sayısının GW Teks çeşidi, en düşük mot sayısının ise, 2006 yılında BA-119 ve 2007 yılında ise Stoneville-453 çeşidinden elde edildiği izlenebilmektedir. Hasat tarihlerine göre ise ortalama mot sayısının 2006 yılında 3.914.66 adet koza $^{-1}$ arasında, 2007 yılında ise 3.95-5.01 adet koza $^{-1}$ arasında değiştiği saptanmıştır. En yüksek mot sayısının 5 Ekim 2006 tarihinde yapılan hasattan elde edildiği, en düşük mot sayısının ise 5 Eylül 2006 (1. hasat) tarihinde yapılan hasattan elde edildiği Çizelge 4.'den izlenebilmektedir. Genel olarak hasatların gecikmesine bağlı olarak mot sayısı artmıştır. Mot oluşumu ve sayısı, bitki içerisindeki sıcaklık ve oransal nemin yüksekliği ve polen canlılığının azalması ile döllenmemiş ovule sayısının (mot) artmasıyla artabilmektedir. Farklı pamuk çeşitlerinin sıcaklığa olan toleranslık 
dereceleri de farklı dönemlerde açan çiçeklerde oluşan koza başına mot sayısını etkileyebilmektedir. Bu durum, çeşitlerin çevre koşullarına tepkilerinin farklılığından kaynaklanmış olabilir. Ayrıca, mot sayısının fazla olması, iplikte boya emmesini engellemekte ve beneklerin oluşumuna neden olabilmektedir. Benzer bulgular, Anthoy ve Calhoun (1996), Trueman ve Wallace (1999), Burke (2002) ve Bölek (2006) tarafından da saptanmıştır.

Çizelge 5. 2006 ve 2007 yıllarında, farklı pamuk çeşitlerinde ve farklı hasat tarihlerinde elde edilen ortalama nep sayısı, lif uzunluğu ve lif inceliği değerleri ile LSD testine göre oluşan gruplar

Table 5. Means of nap number, fiber length and fiber fineness, according to some cultivars and harvesting dates and LSD testing groups in years to 2006 and 2007

\begin{tabular}{|c|c|c|c|c|c|c|}
\hline \multirow{2}{*}{$\begin{array}{l}\text { Çeşitler } \\
\text { Varieties }\end{array}$} & \multicolumn{2}{|c|}{$\begin{array}{c}\text { Nep Sayısı (adet } \mathrm{g}^{-1} \text { ) } \\
\text { Nap Number }\left(\text { number }^{-1} \text { ) }\right.\end{array}$} & \multicolumn{2}{|c|}{$\begin{array}{l}\text { Lif Uzunluğu (mm) } \\
\text { (Fiber Length }(\mathrm{mm})\end{array}$} & \multicolumn{2}{|c|}{$\begin{array}{l}\text { Lif İnceliği (micronaire) } \\
\text { (Fiber Fineness (mic.) }\end{array}$} \\
\hline & 2006 & 2007 & 2006 & 2007 & 2006 & 2007 \\
\hline Stoneville-453 & $106.44 d^{*}$ & $72.22 \mathrm{de}$ & $27.89 \mathrm{bc}$ & $29.01 \mathrm{a}$ & $4.48 \mathrm{~b}$ & $5.15 \mathrm{a}$ \\
\hline SG-125 & $91.56 d$ & $92.67 \mathrm{cde}$ & $27.29 \mathrm{~cd}$ & $28.00 \mathrm{~cd}$ & $4.44 \mathrm{~b}$ & $5.13 \mathrm{a}$ \\
\hline BA-119 & $102.44 \mathrm{~d}$ & $88.22 \mathrm{de}$ & $27.35 \mathrm{~cd}$ & $27.65 d$ & $3.99 \mathrm{e}$ & $4.50 \mathrm{bc}$ \\
\hline Carmen & 155.56 bc & 73.89 de & $28.46 a b$ & $28.49 a b c$ & $4.23 \mathrm{~cd}$ & $5.12 \mathrm{a}$ \\
\hline DPL-388 & $185.56 \mathrm{a}$ & 91.44 de & $27.17 \mathrm{~d}$ & $27.53 \mathrm{~d}$ & $3.93 \mathrm{e}$ & 4.64 bc \\
\hline DPL-5111 & $101.11 \mathrm{~d}$ & $69.22 \mathrm{e}$ & $26.41 \mathrm{e}$ & $27.93 \mathrm{~cd}$ & $4.89 a$ & $5.15 \mathrm{a}$ \\
\hline GW Teks & $138.44 \mathrm{c}$ & 117.22 bc & $28.70 \mathrm{a}$ & $28.83 a b$ & 4.03 de & $4.42 \mathrm{~cd}$ \\
\hline Fantom & $165.78 \mathrm{abc}$ & $165.67 \mathrm{a}$ & $27.89 \mathrm{bc}$ & $28.18 \mathrm{bcd}$ & $3.58 \mathrm{f}$ & $4.22 \mathrm{~d}$ \\
\hline Sayar-314 & $141.11 \mathrm{c}$ & $95.22 \mathrm{~cd}$ & $28.52 \mathrm{a}$ & $27.92 \mathrm{~cd}$ & $4.43 \mathrm{bc}$ & $5.03 \mathrm{a}$ \\
\hline Erşan-92 & $181.11 \mathrm{ab}$ & $121.44 \mathrm{~b}$ & $27.88 \mathrm{bc}$ & $28.74 \mathrm{ab}$ & $4.34 \mathrm{bc}$ & $4.67 \mathrm{~b}$ \\
\hline Means & 136.91 & 98.72 & 27.76 & 28.23 & 4.23 & 4.80 \\
\hline$\underline{\operatorname{LSD}(0.05)}$ & 28.83 & 24.85 & 0.63 & 0.729 & 0.21 & 0.237 \\
\hline \multicolumn{7}{|l|}{$\begin{array}{l}\text { Hasat Tarihleri } \\
\text { Harvesting dates }\end{array}$} \\
\hline $\begin{array}{l}5 \text { Eylül } \\
5 \text { September }\end{array}$ & 119.73 b & 103.20 & 28.35 a & $28.03 \mathrm{~b}$ & 4.17 & $4.89 a$ \\
\hline $\begin{array}{l}20 \text { Eylül } \\
20 \text { September }\end{array}$ & $120.60 \mathrm{~b}$ & 94.50 & $27.47 b$ & $28.57 \mathrm{a}$ & 4.28 & $4.90 \mathrm{a}$ \\
\hline $\begin{array}{l}5 \text { Ekim } \\
5 \text { October }\end{array}$ & $170.40 \mathrm{a}$ & 98.47 & $27.46 \mathrm{~b}$ & $28.09 \mathrm{~b}$ & 4.25 & $4.62 \mathrm{~b}$ \\
\hline $\begin{array}{l}\text { Genel Ortalama } \\
\text { Grand Mean }\end{array}$ & 136.91 & 98.72 & 27.76 & 28.23 & 4.23 & 4.80 \\
\hline$\underline{\operatorname{LSD}(0.05)}$ & 20.66 & Ö.D. & 0.32 & 0.421 & Ö.D. & 0.150 \\
\hline CV (\%) & 28.91 & 24.96 & 2.21 & 2.86 & 4.96 & 6.01 \\
\hline
\end{tabular}

*Aynı harf grubu içerisinde yer alan konular arasında istatistiki olarak önemli düzeyde (0.05) bir farklılık bulunamamıştır.

*Means shown with the same column are not significantly differently at $p=0.05$ probability level.

Çizelge 5'den, ortalama nep sayısının 2006 yilında 91.56-185.56 adet $\mathrm{g}^{-1}$ arasında değiştiği, ortalama 136.91 adet $\mathrm{g}^{-1}$ olduğu; 2007 yilında ise 69.22-165.67 adet $\mathrm{g}^{-1}$ arasında değiştiği ve ortalamanın 98.72 adet $\mathrm{g}^{-1}$ olduğu; en yüksek nep sayısının 2006 yılında DPL-388 ve 2007 yılında ise Fantom çeşidinden elde edildiği; en düşük nep sayısının ise, 2006 yılında SG-125 ve 2007 yılında DPL-5111 çeşidinden elde edildiği görülmektedir. Hasat tarihlerine göre ise nep sayısının 119.73 adet $\mathrm{g}^{-1}$ ile 170.40 adet $\mathrm{g}^{-1}$ arasında değiştiği ve ortalama 136.91 adet $\mathrm{g}^{-1}$ olduğu görülmektedir. En yüksek nep 
sayısının 2006 yılında 5 Ekim 2006 (3. hasat) tarihinde yapılan hasattan elde edildiği, en düşük nep sayısının ise 5 Eylül 2006 (1. hasat) tarihinde yapılan hasattan elde edildiği, 2007 yılında ise hasat tarihleri arasında istatistiki olarak önemli düzeyde bir farklılığın olmadığı saptanmıştır. Bu durum, çeşitlerin genotipik farklılığı ile erken ve geç hasattan dolayı liflerin olgunlaşma durumundan kaynaklanmış olabilir. Antony ve Calhoun (1996), Mangialardi ve Antony (2000) ve Jacobsen ve ark. (2001), iriliği $0.750 \mu \mathrm{m}$ küçük olan lif düğümcüklerine nep olarak tanımlanabildiği, lif düğümcükleri, liflerin iyi olgunlaşmamaları, çırçırlama sistemi, liflerin temizlenme durumu, tohum kabuğu miktarı ve genotipik yapıya göre değişebileceğini bildirmektedir. Ayrıca, denemede çalışılan çeşitlerin nep sayısı genel olarak düşük düzeyde bulunmuştur.

Çizelge 5'den, lif uzunluğunun 2006 yılında $26.41 \mathrm{~mm}$ ile $28.70 \mathrm{~mm}$ arasında değiştiği, ortalama $27.76 \mathrm{~mm}$ olduğu, 2007 yilında ise $27.53 \mathrm{~mm}-29.01 \mathrm{~mm}$ arasında değiştiği ve ortalamanın $28.23 \mathrm{~mm}$ olduğu izlenebilmektedir. Aynı çizelgeden, en yüksek lif uzunluğunun 2006 yılında GW Teks ve 2007 yllında ise Stoneville-453 çeşidinden elde edildiği izlenebilmektedir. Lif uzunluğunun her iki yılda da istatistiki olarak çeşit ve hasat tarihleri arasında önemli farklılıklar oluşmakla birlikte, lif uzunluğu değerlerinin birbirine yakın ancak, hasadın gecikmesiyle azda olsa azaldığı saptanmıştır. Lif uzunluğu çevre koşullarından etkilenmekle birlikte, genetiksel bir özelliktir. Dolayısıyla her çeşidin kendine özgü bir lif uzunluğu bulunmaktadır. Bu nedenle, çeşitler arasında lif uzunluğu yönünden farklılıklar bulunmaktadır. Benzer bulgular, Karademir ve ark. (2003) ve Çopur (2006) tarafından da saptanmıştır. Aynı çizelgeden, hasadın gecikmesiyle lif uzunluğunun azaldığı, en uzun liflerin ise 2006 yılında 5 Eylül'de (1. hasat) 2007 yılında ise 20 Eylül tarihinde yapılan hasattan elde edildiği; geç dönemde açan kozalarda liflerin iyi gelişmediği görülmektedir. Bu durum, 5 ve 20 Eylül'de toplanan pamukların lif oluşum koşullarının 5 Ekim 2006 tarihinde toplanan pamuk liflerinin oluşum koşullarından daha uygun olmasından kaynaklanabilmektedir. Benzer bulgular Civaroğlu (1993), Gülyaşar (1998) ve Çopur ve ark. (1999) tarafından da bildirilmektedir.

Çizelge 5.'den, ortalama lif inceliğinin 2006 yilında 3.58 micronaire ile 4.89 micronaire arasında değiştiği, ortalama 4.23 micronaire olduğu; 2007 yılında ise 4.22 micronaire ile 5.15 micronaire arasında değiştiği, ortalamanın ise 4.80 micronaire olduğu, en ince liflerin Fantom çeşidinden; en kalın liflerin ise ile DPL-5111 çeşidinden elde edildiği izlenebilmektedir. LSD testine göre, farklı lif inceliği gruplarının oluştuğu saptanmıştır. Hasat tarihlerine göre ise, hasadın gecikmesiyle, lif inceliğinin her iki yılda da arttığı izlenebilmektedir. Bu durum, normal koşullarda istenen bir durum olmakla birlikte, liflerde yeterince selülozun birikmediği ve dolayısıyla liflerin zayıf geliştiğini göstermektedir. Benzer bulgular, Kerby ve Ruppenicker (1989), Civaroğlu (1993), Gülyaşar (1998) ve Çopur ve ark. (1999) tarafından da saptanmıştır. Bu nedenle, farklı tarihlerde toplanan kütlülerin birbirine karıştırılmaması gerekmektedir.

Çizelge 6'dan, ortalama lif kopma dayanıklııı̆ının $27.92 \mathrm{~g}$ tex $^{-1}$ ile $33.59 \mathrm{~g}$ tex $^{-1}$ arasında değiştiği ve ortalamanın 29.90 g tex ${ }^{-1}$ olduğu, 2007 yilında ise $30.04 \mathrm{~g} \mathrm{tex}^{-1}$ ile $37.51 \mathrm{~g}$ tex $^{-1}$ arasına değiştiği ve ortalamanın $32.81 \mathrm{~g} \mathrm{tex}^{-1}$ olduğu; her iki yılda da çeşitler arasında önemli düzeyde farklııklar olduğu, en yüksek lif kopma dayanıklılığı değerinin GW Teks; en düşük lif 
kopma dayanıklılığının ise Stoneville-453 çeşidinden elde edildiği izlenebilmektedir. Hasat tarihlerine göre ise lif kopma dayanıklılığı değeri yönünden 2006 yılında önemli düzeyde bir farklığının olmadığı, 2007 yılında ise önemli olduğu ve hasadın gecikmesiyle lif kopma dayanıkılığının azaldığı saptanmıştır. Çizelge 6'dan, en dayanıkı liflerin Carmen, GW Teks ve Fantom çeşitlerinden elde edildiği ve hasadın gecikmesiyle anılan çeşitlerde mukavemet kaybının düşük olduğu izlenebilmektedir. Bu durum, Carmen ve GW Teks çeşitlerinin geççi olması ve vejetasyon süresinin yeterli olması, Fantom çeşidinin ise erkenci olmasından dolayı liflerde selüloz birikiminin yeterli olmasından kaynaklanmış olabilir. Bu durum, anılan çeşitlerin lif kopma dayanıklılığı yönünden yapılacak ıslah çalışmalarında ebeveyn olarak kullanılabileceğini göstermektedir. Benzer bulgular, Harem (2007) tarafından da bildirilmektedir.

Çizelge 6. 2006 ve 2007 yıllarında, farklı pamuk çeşitlerinde ve farklı hasat tarihlerinde elde edilen ortalama lif kopma dayanıklılığı, lif üniformite oranı ve lif elastikiyeti oranı değerleri ile LSD testine göre oluşan gruplar

Table 6. Means of fiber strength, fiber uniformity and fiber elongation, according to some cultivars and harvesting dates and LSD testing groups in years to 2006 and 2007

\begin{tabular}{|c|c|c|c|c|c|c|}
\hline \multirow[t]{2}{*}{$\begin{array}{l}\text { Çeşitler } \\
\text { Varieties }\end{array}$} & \multicolumn{2}{|c|}{$\begin{array}{l}\text { Lif Kopma Dayanıklılığı } \\
\quad\left(\mathrm{g} \mathrm{tex}^{-1}\right) \\
\text { Fiber Strength }\left(\mathrm{g} \mathrm{tex}^{-1}\right)\end{array}$} & \multicolumn{2}{|c|}{$\begin{array}{l}\text { Lif Üniformite Oranı } \\
\text { (\%) } \\
\text { Fiber Uniformity (\%) }\end{array}$} & \multicolumn{2}{|c|}{$\begin{array}{l}\text { Lif Elastikiyeti Oranı (\%) } \\
\text { Fiber Elongation (\%) }\end{array}$} \\
\hline & 2006 & 2007 & 2006 & 2007 & 2006 & 2007 \\
\hline Stoneville-453 & $27.92 f^{*}$ & 31.20 bc & 83.44 & $84.78 a b$ & $6.66 \mathrm{~b}$ & $7.12 \mathrm{c}$ \\
\hline SG-125 & 28.61 ef & $30.04 \mathrm{c}$ & 84.09 & $83.77 \mathrm{abc}$ & $7.61 \mathrm{a}$ & $7.87 a b$ \\
\hline BA-119 & $29.63 \mathrm{cde}$ & 31.90 bc & 83.77 & $84.58 a b$ & $7.31 \mathrm{a}$ & $7.68 b$ \\
\hline Carmen & $31.10 \mathrm{bc}$ & $35.67 \mathrm{a}$ & 84.43 & $84.50 \mathrm{ab}$ & $6.03 c$ & $6.18 \mathrm{e}$ \\
\hline DPL-388 & $30.19 \mathrm{bcd}$ & $32.37 b$ & 83.29 & $82.77 \mathrm{c}$ & $7.37 \mathrm{a}$ & $7.89 a b$ \\
\hline DPL-5111 & 28.50 ef & $33.28 b$ & 83.79 & $84.20 \mathrm{ab}$ & $6.40 \mathrm{bc}$ & $6.69 \mathrm{~d}$ \\
\hline GW Teks & $33.59 \mathrm{a}$ & $37.51 \mathrm{a}$ & 85.30 & $84.69 a$ & $6.60 \mathrm{~b}$ & $7.30 \mathrm{c}$ \\
\hline Fantom & $31.48 \mathrm{~b}$ & $32.58 b$ & 83.63 & 83.36 bc & $7.38 \mathrm{a}$ & $8.12 \mathrm{a}$ \\
\hline Sayar-314 & 29.35 def & 31.49 bc & 84.34 & $82.84 \mathrm{c}$ & $6.07 c$ & $6.47 \mathrm{de}$ \\
\hline Erşan-92 & 28.60 ef & 32.06 bc & 84.34 & 84.87 a & $6.29 \mathrm{bc}$ & $6.59 \mathrm{~d}$ \\
\hline Means & 29.90 & 32.81 & 84.05 & 84.03 & 6.77 & 7.19 \\
\hline $\mathrm{LSD}(0.05)$ & 1.54 & 2.228 & Ö.D. & 1.309 & 0.44 & 0.316 \\
\hline \multicolumn{7}{|l|}{$\begin{array}{l}\text { Hasat Tarihleri } \\
\text { Harvesting dates }\end{array}$} \\
\hline $\begin{array}{l}5 \text { Eylül } \\
5 \text { September }\end{array}$ & 29.75 & $33.69 \mathrm{a}$ & $84.77 \mathrm{a}$ & $84.42 \mathrm{a}$ & $7.03 \mathrm{a}$ & $7.28 a$ \\
\hline $\begin{array}{l}20 \text { Eylül } \\
20 \text { September }\end{array}$ & 29.44 & $33.40 \mathrm{a}$ & $83.98 b$ & $84.64 \mathrm{a}$ & $6.73 b$ & $7.23 a b$ \\
\hline $\begin{array}{l}5 \text { Ekim } \\
5 \text { October }\end{array}$ & 30.51 & $31.34 \mathrm{~b}$ & $83.41 b$ & $83.40 \mathrm{~b}$ & $6.55 c$ & $7.06 \mathrm{~b}$ \\
\hline $\begin{array}{l}\text { Genel Ortalama } \\
\text { Grand Mean }\end{array}$ & 29.90 & 32.81 & 84.05 & 84.03 & 6.77 & 7.19 \\
\hline $\operatorname{LSD}(0.05)$ & Ö.D. & 0.849 & 0.57 & 0.527 & 0.16 & 0.183 \\
\hline CV (\%) & 4.25 & 4.96 & 1.29 & 1.20 & 4.40 & 4.88 \\
\hline
\end{tabular}


Çizelge 6'dan, lif üniformite oranının 2006 yılında \% 83.29 - 85.30 arasında değiştiği, ortalamanın \% 84.05 olduğu; 2007 yılında ise, \% 82.77 - \% 84.87 arasında değiştiği, ortalamanın \% 84.03 olduğu; en yüksek lif üniformite oranının GW Teks çeşidinden elde edildiği; en düşük lif üniformite oranının ise DPL-388 çeşidinden elde edildiği izlenebilmektedir. Hasat tarihlerine göre ise, ortalama lif üniformite oranının birinci yıl \% 83.41-84.77 ve ikinci yıl ise \% 83.40- 84.42 arasında değiştiği ve hasadın gecikmesiyle azaldığı Çizelge 6 'dan izlenebilmektedir. LSD testine göre, lif üniformite oranı yönünden 2006 yılında çeşitler arasında önemli düzeyde bir farklılığın olmadığı, 2007 yılında ise önemli olduğu ve hasat tarihleri yönünden ise her iki yılda önemli farklııklar saptanmıştır. Bu durum, lif gelişiminin iklim koşullarından etkilendiği, 5 Eylül'de (1. Hasat) toplanan kütlü pamukların diğer tarihlerde toplanan kütlülerden lif oluşum koşulları yönünden daha iyi olmasından kaynaklanmış olabilir. Benzer bulgular Gülyaşar (1998) tarafından da saptanmıştır.

Lif elastikiyeti oranı, iplik kalitesini doğrudan etkilemektedir (Faulkner ve ark., 2012). Lif elastikiyeti oranı, stres koşulları ve çeşitlerin genotipik yapılarına bağlıdır. Çizelge 6'dan, farklı çeşitlerle yapılan çalışmada; 2006 yılında, lif elastikiyeti oranının \% $6.03-7.61$ arasında değişstiği, ortalama \% 6.77 olduğu, 2007 yılında ise \% $6.18-8.12$ arasında değiştiği ve ortalamanın \% 7.19 olduğu; en yüksek lif elastikiyeti oranı değerinin SG-125 ve Fantom çeşitlerinde; en düşük lif elastikiyeti oranının ise Carmen çeşidinden elde edildiği izlenebilmektedir. Hasat tarihlerine göre ise hasadın gecikmesiyle lif elastikiyeti oranının azaldığı saptanmıştır. En yüksek lif elastikiyeti oranı her iki yılda da 5 Eylül'de (1. Hasat) yapılan hasattan elde edildiği Çizelge 6'dan izlenebilmektedir. Genel olarak hasat tarihi geciktikçe lif elastikiyeti oranının azaldığı ve çeşitlere göre farklılık gösterdiği söylenebilir. $\mathrm{Bu}$ durum, liflerin kopma dayanıklıı̆ı̆ının azalmasından kaynaklanmış olabilir (Gülyaşar , 1998 ve Ng, 2013).

Çizelge 7'den, pamuk çeşitlerinin farklı renk durumlarının oluştuğu izlenebilmektedir. Pamukta renk, kalıtsal bir özellik olmakla birlikte iklim ve toprak koşullarından etkilenebilmektedir. Ayrıca, liflerin hastalık ve zararlılardan etkilenme derecesi (özellikle Beyazsinek ve afidin fumajin bırakması gibi), liflerin serin hava koşullarında gelişmesi, yağış durumu gibi özellikler pamuk liflerinin rengini değiştirebilmektedir. Çizelge 7'den, Birinci el hasatta, renk derecesinin genel olarak Standart Garanti ve Standart 1, ikinci el hasatta genel olarak Standart 1 ve üçüncü el hasatta ise genel olarak standart 2 renk dereceleri oluşmuştur. 2007 yılında ise özellikle üçüncü el hasatta oluşan renk derecelerinin birinci ve ikinci el hasatlara benzer olduğu ve hasat tarihleri arasında önemli düzeyde bir farklılı̆ıın oluşmadığı gözlenmiştir. Ancak, hasadın gecikmesiyle özellikle geççi çeşitlerde renk değişimleri söz konusu olabilmektedir. Liflerdeki yabancı madde durumu da renk derecesini etkileyebilmektedir. Bu amaçla, farklı tarihlerde ve farklı çeşitlerden elde edilen kütlülerin karıştırılmaması ve farklı depolarda depolanması son derece önemlidir. 
Çizelge 7. 2006 ve 2007 yıllarında, farklı pamuk çeşitlerinde ve farklı hasat tarihlerinde elde edilen liflerdeki renk durumu (sayısal değerler)

Table 7. Obtained color grade according to some cultivars and harvesting dates and LSD testing groups in 2006 and 2007 years (the numerical values)

\begin{tabular}{|c|c|c|c|c|c|c|}
\hline \multirow{3}{*}{$\begin{array}{l}\text { Çeşitler } \\
\text { Varieties }\end{array}$} & \multicolumn{5}{|c|}{$\begin{array}{l}\text { Renk Durumu (Sayısal Değerler) } \\
\text { Color Grade (the numerical values) }\end{array}$} & \\
\hline & \multicolumn{3}{|c|}{2006} & \multicolumn{3}{|c|}{2007} \\
\hline & $\begin{array}{l}\text { First* } \\
\text { Harvest }\end{array}$ & $\begin{array}{l}\text { Second } \\
\text { Harvest }\end{array}$ & $\begin{array}{l}\text { Third } \\
\text { Harvest }\end{array}$ & First Harvest & $\begin{array}{l}\text { Second } \\
\text { Harvest }\end{array}$ & $\begin{array}{l}\text { Third } \\
\text { Harvest }\end{array}$ \\
\hline Stoneville-453 & 21.20 & 21.20 & 41.10 & 21.40 & 31.30 & 41.10 \\
\hline SG-125 & 21.20 & 31.10 & 31.20 & 21.30 & 31.30 & 31.40 \\
\hline BA-119 & 21.40 & 21.30 & 41.10 & 21.30 & 31.30 & 31.30 \\
\hline Carmen & 31.20 & 31.40 & 41.10 & 31.30 & 31.20 & 31.10 \\
\hline DPL-388 & 21.20 & 21.30 & 31.20 & 21.30 & 21.40 & 31.10 \\
\hline DPL-5111 & 31.30 & 31.40 & 31.20 & 31.30 & 31.20 & 31.30 \\
\hline GW Teks & 31.40 & 31.10 & 41.10 & 21.40 & 31.20 & 41.10 \\
\hline Fantom & 31.40 & 31.20 & 31.20 & 31.40 & 21.30 & 31.20 \\
\hline Sayar-314 & 31.40 & 31.40 & 31.20 & 31.30 & 31.30 & 21.20 \\
\hline Erşan-92 & 31.20 & 31.30 & 41.10 & 31.20 & 31.40 & 31.40 \\
\hline
\end{tabular}

*B.H.: 1.Hasat, 5 Eylül: (F:H.:First Harvest: 5 September), İ.H.: 2.Hasat 20 Eylül), S.H.: Second Harvest: 20 September, Ü.H.: 3. Hasat, 5 Ekim, (T.H.: Third Harvest: 5 October)

\section{Sonuçlar}

Harran Ovası koşullarında bazı pamuk çeşitlerinde kütlü pamuk verimi ve farklı hasat tarihlerinin lif teknolojik özelliklerine etkisini belirlemek amacıla 2006 ve 2007 yıllarında yürütülen çalışma sonucunda; 2006 yılı ortalama lif uzunluk uyumu indeksi hariç incelenen diğer özellikler yönünden çeşitler arasında önemli düzeyde bir farklılık olduğu saptanmıştır. Ayrıca hasadın gecikmesiyle, lif teknolojik özelliklerinde kısmen azalma görüldüğü ve renk derecesi yönünden bir derece olumsuz yönde etkilendiği saptanmıştır. Çalışma soncunda; kütlü pamuk verimi yönünden Stoneville-453 ve BA-119, erkencilik oranı yönünden Fantom ve DPL-388, bitki boyu yönünden Sayar 314 ve Erşan-92, 100 tohum ağırlığı yönünden GW Teks, çırçır randımanı yönünden BA-119 ve DPL 388, mot sayısı yönünden BA-119 ve Stoneville-453, nep sayısı yönünden SG-125 ve Stoneville-453, lif uzunluğu yönünden GW Teks ve Carmen, lif inceliği yönünden Fantom çeşidi, lif mukavemeti yönünden GW Teks ve ortalama lif uzunluk uyumu indeksi yönünden GW Teks ve Erşan- 92 çeşitleri ve kopma anındaki lif uzama oranı yönünden ise Fantom ve DPL-388 çeşitlerinin diğer çeşitler göre üstün olduğu ve ıslah çalışmalarında ebeveyn olarak kullanılabileceği saptanmıştır. Ayrıca, Farklı pamuk çeşitlerinin ve farklı tarihlerde toplanan kütlülerin ayrı depolarda depolanması gerektiği sonucuna varılmıştır.

\section{Kaynaklar}

Anonim, 1989. User's Guide to MSTAT-C, An Analysis of Agronomic Research Experiments. Michigan State University, USA.

Anonim, 1997. High Volume Instruments (HVI) Catalog. Costumer information service, No: 40, Volume May, Sweden.

Anonim, 2006. Köy Hizmetleri Genel Müdürlüğü Şanlıurfa Araştırma Enstitüsü Müdürlüğü, Şanlıurfa.

Anonim, 2009. Şanlıurfa Meteoroloji Bölge Müdürlüğü İklim Veri Değerleri, Şanlıurfa.

Anthony, W.S., Calhoun, S., 1996. Ginning Regional Cotton Cultivars at Stonowille. 
Beltwide Cotton Conferencess. Cotton Ginning Conferencess pp. I567-1579.

Baran, F.O., 2013. İkinci Ürün Koşullarında Farklı Ekim Zamanlarının Pamuğun (Gossypium hirsutum L.) Agronomik ve Teknolojik Özellikleri Üzerine Etkisi. Adnan Menderes Üniversitesi Fen Bilimleri Enstitüsü, Tarla Bitkileri Anabilim Dalı, (Yayınlanmamış Yüksek Lisans Tezi), Aydın.

Bölek, Y., 2006. Genetic Variation Among Cotton (G. hirsutum L.) Cultivar for Mote Frequency. Journal of Agricultural Science, 144: 327-331.

Burke, J.J., 2002. Moisture Sensitivity of Cotton Polen: an Emasculation Tool for Hybrid. Agronomy Journal, 94: 883-888.

Civaroğlu, A., 1993. Pamuk Bitkisi Üzerinde Farklı Koza Konumlarının Bazı Teknolojik Özelliklere Etkisi. Nazilli Pamuk Araştırma Enstitüsü Raporları, NazilliAydın.

Çopur, O., 1995. Harran Ovası Koşullarına Uygun Pamuk (G. hirsutum L.) Çeşitlerinin Verim ve Verim Unsurları Arası İlişkilerin Korelasyon ve Path Analizi ile Saptanması. Harran Üniversitesi Fen Bilimleri Enstitüsü. Yüksek Lisans Tezi, Şanlıurfa.

Çopur, O., Oğlakçı, M., Gür, A. 1999. Harran Ovası Koşullarında Farklı Ekim ve Hasat Zamanlarının Pamuk (Gossypium hirsutum L.) Lif Teknolojik Özelliklerine Etkisi Üzerinde Bir Araştırma. Ç.Ü. Ziraat Fakültesi, Türkiye III. Tarla Bitkileri Kongresi, 15-18 Kasım 1999, sayfa 98102, Adana.

Çopur, O., 2006. Determination of Yield and Yield Components of Some Cotton Cultivars in Semi Arid Conditions. Pakistan Journal of Biological Science, 9 (14): 2572-2578.

Çopur, O. 2016. Lif Bitkileri (Çağrılı Bildiri). 20232071 Vizyonuyla TOÇ BIR-SEN Tarım Kongresi. 8-10 Nisan 2016, Kızılcahamam, Ankara (Baskıda).

Demirel, U., Çopur, O., Gür, A. 2016. Screening of Cotton (Gossypium hirsutum L.) for Heat Tolerance Using Multi-trait Approach under Controlled Environment Conditions. Plant Breeding, 135 (1): 8089.

Faulkner, W.B., Hequet, E.F., Wanjura, J. and Boman, R. 2012. Relationships of Cotton Fiber Properties to Ring-spun Yarn
Quality on Selected High Plains Cotton. Textile Res. J. 82: 400-414.

Gülyaşar, L., 1998. Çukurova Bölgesi Koşullarında, Farklı Zamanlarda Toplanan Pamukların, Lif Özellikleri ile İplik Özellikleri Arasındaki İlişkilerin Saptanması (Yüksek Lisans Tezi). Ç.Ü. Fen Bilimleri Enstitüsü Adana.

Harem, E., 2007. Türkiye'de Tescil Edilen Pamuk Çeşitleri. Nazilli Pamuk Araştırma Enstitüsü Müdürlüğü. Yayın No: 65. Nazili/Aydın.

Jacobsen, K.R., Grossman, Y.L., Hsieh, Y.L., Plant, R.E., Lalor, W.F., and Jernstedt, J.A., 2001. Neps, Seed Coat Fragments, and Non-Seed Impurities in Processed Cotton. The Journal of Cotton Sciences, 5:53-67.

Karademir, E., Gençer, O., Karademir, Ç., Başbağ, S., Karahan, H., 2003. Farklı Pamuk Hat/Çeşitlerinin Mardin Koşullarındaki Performanslarının Belirlenmesi. Dicle Üniversitesi Ziraat Fakültesi, Türkiye 5. Tarla Bitkileri Kongresi, Diyarbakır.

Kerby T.A., Ruppenicker, G.F., 1989. Node and Fruiting Branch Position Effect on Fiber and Seed quality Characteristics. Proceed Belt Cotton Prod. Res. Conference, pp. 98-100.

Liu, S.M., Constable, G.A., Reid, P.E., Stiller, W.N., Cullis, B.R., 2013. The Interaction Between Breeding and Crop Management in Improved Cotton Yield. Field Crops Research, 148: 49-60.

Mangialardi, G.J., Antony, W.S., 2000. Feasibility of Applying Seed Cotton Cleaning Principles to Lint Cleaning. The Journal of Cotton Sciences, 4:183-192.

Meredith, W.R.JR., Bridge, R.R., 1973. Yield and Yield Component and Fiber Property Cariation of Cotton (Gossypium hirsutum L.) Within and Among Environments. Crop Sci., 13: 307-312.

$\mathrm{Ng}$, E.H. 2013. Genetics of Cotton Fiber Elongation. Doctor of Philosophy. Texas A\&M University, Department of Soil and Crop Science, USA.

Özbek, N., Bintaş, E., Yılmaz, E. ve Beşenk, Z. Y., 2005. Pamuk Bitkisinde Farklı Bitki İzleme Teknikleri Kullanılarak Bitki Gelişiminin İzlenmesi İle Su Yönetimi. Proje No: TAGEM/TA/03/02/02/005, Nazili/Aydın.

Trueman, S.J., and Wallace., H.M., 1999. Pollination and Resource Constraints on 
Fruit Set and Fruit Size of Persoonia rigida (Proteaceae). Annals of Botany, 83: 145-155.
Worley, S.J.R, Harmon, H.R, Harrel, D.C., Culp, T.W. 1976. Ontogenetic Model of Cotton Yield. Crop Science, 16: 30-34. 